\title{
TINGKAT LITERASI MEDIA BERBASIS KOMPETENSI INDIVIDU DI KALANGAN SISWA SMA NEGERI 17 MAKASSAR
}

\author{
Rahmawati Latief \\ Jurusan Jurnalistik, Fakultas Dakwah dan Komunikasi \\ Universitas Islam Negeri (UIN) Alauddin Makassar \\ Email : rahmawati.latief@uin-alauddin.ac.id
}

\begin{abstract}
Abstrak
Nowadays the mass media is experiencing very rapid development. Various positive and negative impacts certainly cannot be ignored. This impact hits parents, adults, teenagers and children. Adolescents are a group that is vulnerable to the negative effects of mass media by which media literacy movements emerge as solutive actions over concerns about negative media influences. The ability of media literacy is very necessary so that the media can be used intelligently and wisely. The purpose of this study are: (1) To determine the level of technical skills (technical expertise) of SMA Negeri 17 Makassar students in accessing computer and internet media; (2) To describe the level of critical understanding (critical understanding) of SMA Negeri 17 Makassar students in analyzing and evaluating computer and internet media content; (3) To understand the level of communicative abilities (communication skills) of SMA Negeri 17 Makassar students in establishing social relations through internet media and creating creative internet media content; (4) To find out the level of media literacy of SMA 17 Makassar students. The results of this study indicate that cumulatively the level of technical skill ability is at $99.5 \%$, the level of critical understanding capability is at $74.7 \%$, the level of communicative abilities is a value of $110.3 \%$. By referring to the values above, the level of media literacy of Makassar 17 Public High School students is $94.83 \%$ or at the Medium level.
\end{abstract}

Keyword : Media Literacy, Individual Competence, Technical Skills, Critical Understanding, Communication Skills.

\section{A. PENDAhuluan}

Dunia kita ibarat supermarket besar yang dihiasi pesan-pesan media massa yang semakin beragam bentuk dan jenisnya. Kehidupan manusia disesaki dengan media massa (media-saturated), yang hadir di mana-mana dan menjadi kendaraan penghubung berbagai belahan dunia yang berbeda latar belakang geografis, budaya, suku, agama dan pendidikan. Ledakan perkembangan teknologi komunikasi turut memacu munculnya beragam media massa yang baru (new media) yang menyebabkan terjadinya kebanjiran informasi (the flood of information). Sebagai contoh, di Amerika Serikat hampir 65.000 judul buku dipublikasikan setiap tahun yang tersedia di perpustakaan umum maupun toko buku online, belum lagi dengan penggunaan fasilitas komputer pribadi yang terhubung dengan internet sehingga kita mampu mengakses 3000 surat kabar online, bahkan World Wide Web 
menawarkan 2,5 trilyun dokumen yang dapat diakses dengan mudah tanpa mengenal batas dan waktu ${ }^{1}$.

Di Indonesia sendiri penggunaan media cetak, media elektronik dan media baru (internet), televisi merupakan media yang paling banyak di konsumsi oleh masyarakat. Penelitian yang diadakan surat kabar Kompas pada tanggal 20-21 Agustus 2003 dengan menggunakan responden sebanyak 950 orang dengan usia minimal 17 tahun dan dilakukan di kota Jakarta, Yogyakarta, Surabaya, Padang, Makassar, Banjarmasin, Pontianak, Manado dan Jayapura mengatakan bahwa dalam sehari jumlah responden yang menonton televisi adalah 1-2 jam. (25,5\%); 3-4 jam (38,4\%); 5-6 jam (22,5\%); dan 7 jam atau lebih $(13,6 \%)^{2}$. Hal ini menunjukkan bahwa pengunaan televisi cukup signifikan dan mengambil porsi waktu yang banyak dari khalayak.

Data riset dari MarkPlus Insight juga menunjukkan bahwa jumlah pengguna internet di Indonesia pada tahun 2011 sudah mencapai 55 juta orang, meningkat dari tahun sebelumnya di angka 42 juta $^{3}$. Sebagai tambahan, data terbaru menunjukkan bahwa pada tanggal 26 Januari 2017, perusahaan riset We Are Social kembali mengumumkan laporan terbaru mereka terkait perkembangan penggunaan internet di seluruh dunia. Hasilnya, mereka menyebut Indonesia sebagai negara dengan pertumbuhan jumlah pengguna internet terbesar di dunia. Hanya mempunyai sekitar 88,1 juta pengguna internet pada awal tahun 2016, jumlah pengguna internet di tanah air telah naik sebesar 51 persen ke angka 132,7 juta pengguna pada awal $2017 \mathrm{ini}^{4}$. Paparan ini menunjukkan tidak dapat dipungkiri bahwa animo manusia terhadap penggunaan internet sebagai media komunikasi dan informasi terus meningkat. Kehadiran internet telah membawa revolusi serta inovasi pada cara manusia berkomunikasi dan memperoleh informasi. Internet berhasil mengatasi masalah klasik manusia, karena keterbatasan jarak, ruang, dan waktu tidak lagi menjadi kendala berarti.

\footnotetext{
${ }^{1}$ Kawamoto dalam W.James Potter. Media literacy, third edition. (California: Sage Publications, Inc, 2005) hal. 25

${ }^{2}$ Rini Darmastuti, Turnomo Rahardjo, M. Antonius Birowo, Dewi Kartika Sari, Husain, M.N.,Sunarto., Hastjarjo,S.,Febriyanto, Tomi.,Herfiady,Junaedi.F., \& Budi, S. Literasi media \& kearifan lokal, konsep dan aplikasi. (Salatiga : UKSW kerjasama UBCHEA, ASPIKOM \& BUKU, 2012) hal. 48

${ }^{3}$ Rini Darmastuti, Turnomo Rahardjo, M. Antonius Birowo, Dewi Kartika Sari, , Husain, M.N., Sunarto., Hastjarjo, S.,Febriyanto, Tomi.,Herfiady,Junaedi.F., \& Budi, S. Literasi media \& kearifan lokal, konsep dan aplikasi. (Salatiga : UKSW kerjasama UBCHEA, ASPIKOM \& BUKU, 2012) hal. 70

${ }^{4}$ Aditya Hadi Pratama, "Perkembangan Pengguna Internet di Indonesia Tahun 2016 Terbesar di Dunia", https://id.techinasia.com/pertumbuhan-pengguna-internet-di-indonesia-tahun-2016 (diakses pada 22 Oktober 2018)
} 
Data di atas mendeskripsikan bahwa terpaan media massa begitu sangat dominan dan signifikan dalam kehidupan masyarakat. Media massa tidak hanya berperan sebagai ruang publik yang menjadi wahana dialog antar bagian dalam masyarakat untuk kepentingan-kepentingan sosial, budaya, agama, pendidikan, politik dan ekonomi, tetapi yang tak kalah pentingnya media massa menjadi industri yang menggiurkan pihak korporat demi kepentingan komersial yang berorientasi pada keuntungan materi dan mengabaikan kepentingan publik. Fenomena ini menjelma pada banyaknya tampilan konten media yang buruk khususnya media elektronik atau media penyiaran. Hal ini bisa dilihat dari pengaduan mengenai isi siaran yang dilayangkan ke Komisi Penyiaran Indonesia (KPI) terkhusus pada data tahun 2012, KPI Pusat menerima jumlah pengaduan publik yang jauh lebih besar dibandingkan tahun-tahun sebelumnya dan tahun-tahun setelahnya. Pengaduan yang masuk ke KPI berjumlah 43.552 pengaduan. Jumlah ini telah menjadi jumlah pengaduan terbesar yang telah diterima KPI. Pada tahun-tahun sebelumnya hingga 2015, secara berturut-turut jumlah pengaduan tentang isi siaran adalah sebagai berikut: 1.335 (2007), 3.588 (2008), 7.634 (2009), 26.489 (2010), dan 3.856 (2011) 9.661 (2013) $8.137(2015)^{5}$

Kecenderungan tersebutlah yang tentunya menuntut pengguna media untuk memiliki pemahaman yang lebih tentang media. Pemahaman inilah yang akan memberikan pengaruh pada pola perilaku atau keputusan untuk menggunakan media tersebut atau tidak. Oleh karenanya, gerakan Literasi Media menjadi penting dalam masyarakat. Media literacy atau Literasi Media pada mulanya dikonsepsikan sebagai keterampilan untuk memahami bagaimana media menyampaikan pesan-pesan dan mengapa demikian. Melek media merupakan upaya pembelajaran bagi khalayak media sehingga menjadi khalayak yang berdaya hidup di tengah dunia yang disebut dunia sesak media (media-saturated) ${ }^{6}$ Gerakan literasi media muncul sebagai bentuk kekhawatiran akan pengaruh media yang lebih berdampak buruk bagi masyarakat. Di samping itu dengan kemampuan literasi media masyarakat maka kekuatan pemilik dan pelaku media bisa lebih dikontrol sehingga kekuatan antara media dengan masyarakat konsumen media bisa berimbang, tidak ada yang lebih dominan dan pada akhirnya dampak negatif media mampu direduksi dengan

\footnotetext{
${ }^{5}$ www.kpi.go.id

${ }^{6}$ Yosal Iriantara. Literasi Media, apa, mengapa dan bagaimana. (Bandung: Simbiosa Rekatama Media, 2009) hal. 79.
} 
pemahaman literasi media atau melek media yang berkonsentrasi melahirkan khalayak yang cerdas dalam mengakses, menganalisis, mengevaluasi pesan media massa bahkan mampu menghasilkan produk media massa yang positif.

Salah satu kerangka konsep yang digunakan untuk mengukur tingkat literasi media pada seseorang adalah Individual Competence Framework (Kerangka Kompetensi Individu) yang telah diuji penggunaannya dalam mengukur tingkat literasi media pada masyarakat di beberapa negara Eropa oleh EAVI (European Association For Viewers Interests) consortium, The Ministère de I'Education Nationale Française (CLEMI), The Universitat Autonòma de Barcelona (UAB), The Université Chatolique de Louvain (UCL) dan The Univerity of Tampere (UTA). Framework ini pada dasarnya merupakan hasil penelitian yang dipersiapkan untuk European Commission dan telah diberlakukan di negara-negara Eropa sejak tahun 2009.

Individual Competence Framework adalah kemampuan seseorang untuk mengggunakan dan memanfaatkan media yang dilihat berdasarkan kompetensi personal (Personal Competence) dan kompetensi sosial (Social Competence) seseorang. Personal Competence terdiri atas dua kriteria atau indikator yaitu technical skill (kemampuan teknik) dan critical understanding (kemampuan mengkritisi/menganalisis). Sedangkan Social Competence terdiri atas satu kriteria atau indikator yaitu communicative abilities (kemampuan berkomunikasi dengan media). Kerangka inilah yang nantinya digunakan untuk mengukur tingkat literasi media di kalangan siswa SMA Negeri 17 Makassar.

Berdasarkan pemaparan di atas, peneliti tertarik untuk melakukan penelitian tingkat literasi media berbasis kompetensi individu di kalangan siswa SMA Negeri 17 Makassar. Alasan pemilihan siswa SMA karena berdasarkan standar usia mereka dikategorikan golongan remaja yang rentan terterpa dampak buruk konten media sedangkan alasan pemilihan SMA Negeri 17 karena merupakan salah satu sekolah unggulan di Kota Makassar. Adapun rumusan masalahnya sebagai berikut:

1. Bagaimana tingkat technical skill siswa SMA Negeri 17 Makassar dalam mengakses media komputer dan internet?

2. Bagaimana tingkat critical understanding siswa SMA Negeri 17 Makassar dalam menganalisis dan mengevaluasi konten media komputer dan internet? 
3. Bagaimana tingkat communicative abilities siswa SMA Negeri 17 Makassar dalam menjalin relasi sosial melalui media internet dan menciptakan konten media internet yang kreatif?

4. Bagaimana tingkat literasi media siswa SMA Negeri 17 Makassar?

\section{B. TINJAUAN TEORITIS}

\section{Memahami Literasi Media}

Literasi media memiliki sejarah yang cukup panjang yang dimulai tahun 1964 saat UNESCO mengembangkan prototipe model program media yang akan dijalankan di seluruh dunia, tapi konon jauh sebelumnya, yakni pada tahun 1930, Inggris sudah mulai mengembangkan literasi media. Pada waktu itu, baru dua negara yang menaruh perhatian pada literasi media yakni Inggris dan Australia. Kalangan pendidik di dua negara itu menyarankan pelaksanaan pendidikan untuk mencapai melek media agar anak-anak dan remaja dapat secara kritis melihat dan membedakan apa yang baik dan apa yang buruk dari media massa. ${ }^{7}$

Di Indonesia sendiri, kajian literasi media baru popular di sekitar awal tahun 2000an yang ditandai dengan kampanye literasi media ke publik yang digagas oleh perguruan tinggi yang memiliki program studi ilmu komunikasi, sejumlah LSM seperti Masyarakat Peduli Media (MPM), Yayasan Pengembangan Media Anak (YPMA), lembaga pemerintah seperti Komisi Penyiaran Indonesia (KPI) Pusat dan Daerah dan kelompok-kelompok masyarakat tertentu. Di pertengahan tahun 2000-an, seminar, workshop dan konferensi literasi media di perguruan tinggi semakin marak, tidak hanya pada tingkat lokal dan nasional bahkan pada tingkat internasional. Demikian pula publikasi literasi media, tidak sebatas artikel popular dalam media massa tetapi juga telah merambah artikel ilmiah pada jurnal lokal maupun nasional yang telah terakreditasi.

\footnotetext{
${ }^{7}$ R. Hobbs (1999). "The acquisition of media literacy skills among Australian adolescent". Journal of Broadcasting and Media. http://www.interact.uoregon.edu/MediLit/mls/readingarticles/hobbs/australia.html.
} 
Istilah literasi media memiliki banyak padanan misalnya melek-media, media education, paedagogy of media literacy dan media studies ${ }^{8}$, critical thinking, information processing ${ }^{9}$ namun perbedaan istilah ini tidak menunjukkan perbedaan substansi. Lalu apa sebenarnya makna dari literasi media? ${ }^{10}$ menjelaskan bahwa "literacy is the ability to access, analyze, evaluate, and communicate messages in a variety of forms" Literasi adalah kemampuan mengakses, mengevaluasi, menganalisis dan mengkomunikasikan pesan dalam berbagai bentuknya. Senada dengan itu The New Mexico Media Literacy menjelaskan bahwa "media literacy as the ability to access, analyze, evaluate, and create messages in various media" Literasi media adalah kemampuan mengakses, menganalisis, mengevaluasi dan menciptakan pesan-pesan dalam berbagai media.

Lebih spesifik lagi Silverblatt dan Eliceiri ${ }^{11}$ menjelaskan bahwa "media literacy is a critical-thinking skill that enables audiences to decipher the information that they receive through the channels of mass communications and empowers them to develop independent judgments about media content" Literasi media adalah kecakapan berpikir kritis yang memungkinkan khalayak menguraikan informasi yang mereka terima melalui saluran komunikasi massa (media massa) dan memberdayakan kemampuan khalayak untuk mengembangkan penilaian independen tentang isi media.

Pernyataan ini didukung oleh definisi literasi media yang diberikan oleh Northwest Media Literacy Project "the ability to critically asses media messages in order to understand their impact on us, our communities, our society, and our planet; it is also a movement to raise awareness of media and their influence" Literasi media adalah kemampuan menilai secara kritis pesan-pesan media agar memahami impaknya terhadap kita, komunitas, masyarakat dan dunia. Kegiatan ini juga merupakan sebuah pergerakan untuk meningkatkan kesadaran terhadap media dan pengaruhnya.

\footnotetext{
${ }^{8}$ Yosal Iriantara. Literasi Media, apa, mengapa dan bagaimana. (Bandung: Simbiosa Rekatama Media, 2009) hal. 85.

${ }^{9}$ W. James Potter. Theory of media literacy, a cognitive approach. (California: Sage Publications, Inc,2004) hal. 130

${ }^{10}$ R. Hobbs, (1997). Expanding the concept of literacy. In R. Kubey (Ed.), Media literacy in the information age (pp. 163-183), New Brunswick, NJ: Transaction.

${ }^{11}$ A. Silverblatt,., \& E.M.E Eliceiri, Dictionary of media literacy. (Westport, CT: Greenwood Press.1997) hal 60.
} 


\section{Individual Competence Framework}

Dalam penelitian ini, analisis yang dilakukan dengan menggunakan Individual Competence Framework (Kerangka Kompetensi Individu). Kemampuan literasi media dapat diukur dengan menggunakan Individual Competence Framework dalam Final Report Study on Assessment Criteria for Media Literacy Levels tahun 2009 yang dilaksanakan oleh European Commision. Sebelumnya framework tersebut digunakan untuk mengukur tingkat literasi media pada masyarakat di negara-negara Uni Eropa.

Individual Competence adalah kemampuan seseorang dalam menggunakan dan memanfaatkan media. Di antaranya kemampuan untuk menggunakan, memproduksi, menganalisis dan mengkomunikasikan pesan melalui media. Individual competence ini terbagi dalam dua kategori:

1. Personal competence, yaitu kemampuan seseorang dalam menggunakan media dan menganalisis konten-konten media. Personal competence ini terdiri dari dua kriteria, yaitu:

a. Technical skills, yaitu kemampuan teknik dalam menggunakan media. Artinya, seseorang mampu mengoperasikan media dan memahami semua jenis instruksi yang ada didalamnya. Technical skills ini mencakup beberapa kriteria, yaitu :

1). Kemampuan untuk menggunakan komputer dan internet (computer and internet skills)

2). Kemampuan untuk menggunakan media secara aktif (balances and active use of media)

3). Kemampuan menggunakan internet yang tinggi (advanced internet use)

b. Critical understanding, yaitu kemampuan kognitif dalam menggunakan media seperti kemampuan memahami, menganalisis dan mengevaluasi konten media. Kriterianya antara lain:

1). Kemampuan memahami konten dan fungsi media (undestanding media content and its functioning)

2). Memiliki pengetahuan tentang media dan regulasi media (knowledge about media and media regulation)

3). Perilaku pengguna dalam menggunakan media (use behavior) 
2. Social competence, yaitu kemampuan seseorang dalam berkomunikasi dan membangun relasi sosial lewat media serta mampu memproduksi konten media. Social competence ini terdiri dari Communicative abilities, yaitu kemampuan komunikasi dan partisipasi melalui media. Communicative abilities ini mencakup kemampuan untuk membangun relasi sosial serta berpartisipasi dalam lingkungan masyarakat melalui media. Selain itu communicative abilities ini juga mencakup kemampuan dalam membuat dan memproduksi konten media mengukur tingkat kemampuan literasi media. Communicative abilities ini mencakup beberapa kriteria, yaitu :

1) Kemampuan berkomunikasi dan membangun relasi sosial melalui media (sosial relations)

2) Kemampuan berpartisipasi dengan masyarakat melalui media (citizen participation)

3) Kemampuan untuk memproduksi dan mengkreasikan konten media (content creation)

Setelah mengetahui bobot tiap komponen penilaian literasi media tersebut, selanjutnya adalah menganalisis hasil perhitungan kuesioner dan memadukannya dengan bobot masing-masing komponen. Hasil perhitungan tersebut selanjutnya akan menentukan tingkat kemampuan literasi media. Dalam hal ini, tingkat kemampuan literasi media dibedakan menjadi tiga kategori, yaitu basic, medium, dan advanced.

1. Basic, kemampuan dalam mengoperasikan media tidak terlalu tinggi, kemampuan dalam menganalisis konten media tidak terlalu baik dan kemampuan berkomunikasi lewat media terbatas. Nilai untuk tingkat kemampuan basic ini adalah di bawah 70 .

2. Medium, kemampuan mengoperasikan media cukup tinggi, kemampuan dalam menganalisis dan mengevaluasi konten media cukup bagus, serta aktif dalam memproduksi konten media dan berpartisipasi secara sosial. Nilai untuk tingkat kemampuan medium ini adalah 70-130.

3. Advanced, kemampuan mengoperasikan media sangat tinggi, memiliki pengetahuan yang tinggi sehingga mampu menganalisis konten media secara mendalam, serta mampu berkomunikasi secara aktif melalui media. Nilai untuk tingkat kemampuan ini adalah di atas 130. 


\section{METODE PENELITIAN}

Jenis penelitian ini adalah penelitian kuantitatif dengan format deskriptif dengan metode survei dengan menggunakan kuesioner sebagai instrumen pengumpulan datanya. Lokasi penelitian dilakukan di SMA Negeri 17 Makassar yang beralamat di Jln. Sunu No. 11, Makassar. Dalam konteks penelitian ini, peneliti mengambil populasi yaitu siswa kelas X, XI, XII SMA Negeri 17 Makassar dengan jumlah keseluruhan siswa adalah 1065 siswa dengan rincian 410 siswa laki-laki dan 655 siswa. Teknik sampling yang digunakan adalah teknik sampling probabilitas atau probability sampling. Yaitu, sampel ditarik berdasarkan probabilitas, yang membuat setiap unsur populasi memiliki kemungkinan yang sama untuk dipilih melalui perhitungan secara sistematis. Berdasarkan data populasi yang ada, maka untuk menghitung jumlah sampel peneliti menggunakan Rumus Slovin. Rumus Slovin digunakan untuk menetukan ukuran sample dari populasi yang diketahui jumlahnya ${ }^{12}$ Perhitungannya sebagai berikut :

$$
n=\frac{N}{1+N \rho^{2}}
$$

Keterangan:

$$
\begin{aligned}
\mathrm{n}= & \text { ukuran sampel } \\
\mathrm{N}= & \text { ukuran populasi } \\
\mathrm{e}= & \text { kelonggaran ketidaktelitian karena kesalahan pengambilan sampel yang } \\
& \text { dapat ditolerir, dalam penelitian ini akan digunakan persentase } \\
& \text { kelonggaran yaitu } 10 \%, \text { kemudian e ini dikuadratkan. }
\end{aligned}
$$

Berdasarkan rumus tersebut diperoleh jumlah sampel sebagai berikut :

$$
\begin{aligned}
n=\frac{N}{1+N e^{2}} & =\frac{1065}{1+1065 \cdot(0,1)^{2}}=\frac{1065}{1+1065 \cdot(0,01)}=\frac{1065}{1+10,65} \\
& =\frac{1065}{11,65} \quad=91,41 \text { Orang }=91 \text { siswa }
\end{aligned}
$$

\footnotetext{
${ }^{12}$ Rachmat Kriyantono. Teknik Praktis Riset Komunikasi: Disertai Contoh Praktis Riset Media, Public Relations, Advertising, Komunikasi Organisasi, Komunikasi Pemasaran. (Jakarta: Kencana, 2006). Hal 26.
} 
Kemudian sampel yang terpilih ini akan diambil dengan menggunakan metode penarikan sampel probabilitas Proportionate Stratified Random Sampling, metode ini digunakan apabila populasi mempunyai anggota/unsur yang tidak homogen dan berstrata secara proporsional. Adapun rincian pengambilan sampel adalah sebagai berikut :

Tabel 1 Jumlah Populasi dan Sampel

\begin{tabular}{|c|c|c|c|}
\hline No. & Kelas & $\begin{array}{c}\text { Populasi } \\
(\mathbf{N})\end{array}$ & Sampel (n) \\
\hline 1 & X1-X10 & 358 & 31 \\
\hline 2 & XI1-XI8 & 283 & 24 \\
\hline 3 & XII1-XII12 & 424 & 36 \\
\hline & Jumlah & 1065 & 91 \\
\hline
\end{tabular}

Sumber : Data Sekunder yang diperoleh dari SMAN 17 Mks, 2018

Untuk mendapatkan data yang dibutuhkan dalam penelitian ini, maka digunakan teknik pengumpulan data seperti observasi dan kuesioner. Dalam penelitian ini teknik analisis data yang akan digunakan adalah analisis kuantitatif, data yang diperoleh dari pengisian kuesioner atau angket. Data tersebut diolah dan dianalisis dengan tabel tunggal yang menggunakan aplikasi SPSS (Statistical Product Service Solution) versi 22. Untuk menghindari bias pertanyaan, maka pertanyaan disusun berdasarkan indikator-indikator dari variabel kompetensi individu ini terbagi 2 sub variabel, yaitu pertama. keahlian teknis (Technical Skill) dengan indikator (a) kemampuan menggunakan komputer dan internet, (b) keseimbangan penggunaan media, dan (c) frekuensi penggunaan media. Kedua, sub variabel pemahaman kritis (Critical Understanding) dengan indikator (a) Pemahaman konten / teks media, (b) Pengetahuan regulasi media, (c) perilaku bermedia. Variabel kompetensi sosial dengan sub variabel kemampuan berkomunikasi (Communicative Abilities) dengan indikator (a) kemampuan interaksi sosial, (b) partisipasi sosial, dan (c) menciptakan kreasi konten media. Adapun kerangka konsep penelitian adalah sebagai berikut : 


\section{Bagan 1. Kerangka Konseptual Penelitian}

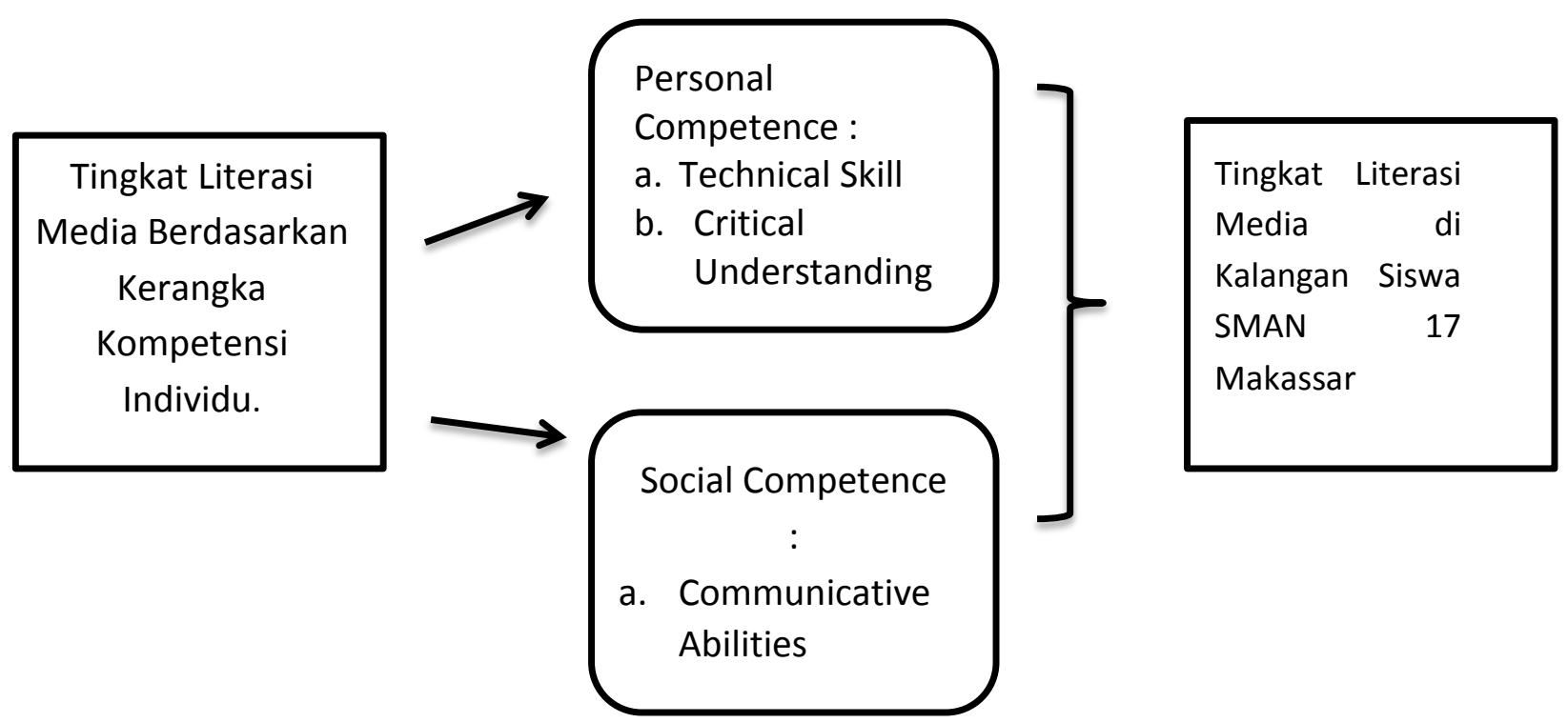

Sumber : Data olahan hasil peneliti, 2018

\section{HASIL PENELITIAN}

Penelitian ini terfokus

pada satu aspek penilaian yaitu mengukur tingkat literasi media berbasis kompetensi individu dengan tiga bagian kajian yaitu technical skill, critical understanding, dan communicative abilities. Peneliti melakukan uji validitas dengan standar angka minimal 0,2 dan dibandingkan dengan angka-angka yang ada di kolom Corrected Item-Total Correlation pada output uji validitas melalui Scale Reliability dengan bantuan program IBM SPSS Statistics 22. Bila angka korelasi yang terdapat pada kolom Corrected Item-Total Correlation berada dibawah $0,2(\mathrm{r}<0,2)$ atau bertanda negative (-), maka dinyatakan tidak valid (gugur). Sebaliknya bila angka korelasinya diatas $0,2(\mathrm{r}>0,2)$ maka dinyatakan valid. Adapun hasil uji validitas instrument penelitian sebagai berikut.:

Tabel 2 Blue Print Kuesioner Tingkat Literasi Media Berbasis Kompetensi Individu Setelah Uji Validitas

\begin{tabular}{|c|c|c|c|c|c|}
\hline \multirow{2}{*}{ No. } & \multirow{2}{*}{ Aspek } & \multirow{2}{*}{ Indikator } & \multicolumn{2}{|c|}{ Aitem } & \multirow{2}{*}{ Total } \\
\hline & & & $\mathbf{F}$ & UF & \\
\hline \multirow[t]{2}{*}{1} & \multirow[t]{2}{*}{ Technical skill } & $\begin{array}{l}\text { Computer and } \\
\text { internet skills }\end{array}$ & $2,3,4,5,7$ & 6 & 6 \\
\hline & & Balanced and & 11 & - & 1 \\
\hline
\end{tabular}




\begin{tabular}{|c|c|c|c|c|c|}
\hline & & $\begin{array}{l}\text { active use of } \\
\text { media }\end{array}$ & & & \\
\hline & & $\begin{array}{c}\text { Advanced } \\
\text { internet use }\end{array}$ & $14,18,19$ & - & 3 \\
\hline & & $\begin{array}{c}\text { Understanding } \\
\text { media content } \\
\text { and its } \\
\text { functioning }\end{array}$ & $1,2,3,4,5,8$ & 6 & 7 \\
\hline 2 & $\begin{array}{c}\text { Critical } \\
\text { understanding }\end{array}$ & $\begin{array}{l}\text { Knowledge } \\
\text { About media } \\
\text { And media } \\
\text { Regulation }\end{array}$ & $9,10,12$ & 11,14 & 5 \\
\hline & & $\begin{array}{c}\text { User } \\
\text { Behaviour }\end{array}$ & 16,19 & 17 & 3 \\
\hline & & $\begin{array}{l}\text { Social } \\
\text { relations }\end{array}$ & $1,2,3$ & - & 3 \\
\hline 3 & $\begin{array}{c}\text { Communicative } \\
\text { abilities }\end{array}$ & $\begin{array}{c}\text { Citizen } \\
\text { participation }\end{array}$ & $5,6,7$ & - & 3 \\
\hline & & $\begin{array}{l}\text { Content } \\
\text { creation }\end{array}$ & 8,9 & - & 2 \\
\hline & Total & & 28 & 5 & 33 \\
\hline
\end{tabular}

Sumber: Analisis Peneliti, 2018

Hasil uji validitas menunjukkan dari 52 butir pertanyaan dalam kuesioner atau skala maka ada 19 pertanyaan yang gugur atau tidak valid, maka hasil akhir diperoleh 33 pertanyaan yang valid. Kemudian peneliti melakukan uji reliabilitas pada penelitian ini menggunakan teknik Cronbach Alpha dengan bantuan program IBM SPSS Statistics 22. Hasil pengujian reliabilitas dapat diuraikan sebagai berikut.

Tabel 3. Uji Reliabilitas Skala Tingkat Literasi Media Berbasis Kompetensi Individu

\begin{tabular}{|c|c|c|}
\hline Variabel & Alpha (a) & Status \\
\hline Technical skill & 0,778 & Reliabel \\
\hline Critical understanding & 0,788 & Reliabel \\
\hline Communicative abilities & 0,825 & Reliabel \\
\hline
\end{tabular}

Sumber: Data primer diolah dari kuesioner, 2018

Hasil uji reliabilitas pada tabel 3 tersebut menyatakan bahwa instrument penelitian ini memiliki nilai alpha $(\alpha)>0,6$ sehingga dapat dinyatakan reliabel (andal).

Berdasarkan pengolahan data hasil kuesioner yang sudah melalui uji validitas dan uji reliabilitas maka ditemukan jumlah akumulasi skor sebagai berikut : 
Tabel 4. Jumlah akumulasi Skor

\begin{tabular}{|l|l|}
\hline Aspek & Persentase Skor \\
\hline Techincal Skill & $99,5 \%$ \\
\hline Critical Understanding & $74,7 \%$ \\
\hline Communicative Abilities & $110,3 \%$ \\
\hline
\end{tabular}

Sumber : Data primer diolah dari kuesioner, 2018

Jadi nilai akumulasi ketiga aspek ini akan dirata-ratakan sebagai berikut : 99,5\% +74,7\%

$+110,3 \% / 3=94,83 \%$ artinya nilai ini masuk dalam kategori MEDIUM.

Ini berarti tingkat literasi media berbasis kompetensi individu dikalangan siswa SMAN 17 Makassar berada pada level Medium.

\section{PEMBAHASAN}

Dari hasil data melalui kuesioner yang telah diolah dari setiap pernyataan kemudian diakumulasikan maka telah ditemukan bahwa akumulasi aspek Technical Skill sebesar 99,5\%, akumulasi aspek Critical Understanding sebesar 74,7\%, dan akumulasi aspek Communicative Abilities sebesar 110,3\%. Data ini menunjukkan bahwa kemampuan literasi media siswa SMA Negeri 17 berada pada level Medium dengan nilai rata-rata adalah $94,83 \%$.

Ini berarti bahwa siswa memiliki kemampuan mengoperasikan media cukup tinggi (technical skill), kemampuan dalam menganalisis dan mengevaluasi konten media cukup bagus (critical understanding), serta aktif dalam memproduksi konten media dan berpartisipasi secara sosial (communicative abilities).

Namun demikian data yang menarik juga ditemukan, misalnya saja ada 46,2\% responden yang sangat berhati-hati memasukkan data personal ketika melakukan registrasi di aplikasi atau website media online, akan tetapi disisi lain ada 42,6\% responden yang tidak pernah melakukan cross check atau pemeriksaan satu isu informasi berita diberbagai portal/situs. Ini menunjukkan bahwa informasi yang berhubungan dengan kepentingan pribadi mendapatkan perhatian penuh dari responden, sedangkan isu informasi berita tidak mendapatkan perhatian dari responden. Hasil ini juga berkorelasi 
dengan temuan bahwa 49,5\% responden tidak pernah memberikan kritik terhadap isu-isu di media sosial.

Data menarik lainnya yang ditemukan bahwa 59,3\% responden setuju bahwa ujaranujaran kebencian (hate speech) jauh lebih banyak tersebar di media sosial daripada di media televisi, radio dan surat kabar. Hal ini menunjukkan bahwa siswa telah menyadari tersebarnya ujaran-ujaran kebencian lebih banyak diakses di media sosial. Data yang cukup mengejutkan bahwa 40,7 \% responden yang memilih untuk tidak mengupload foto selfie di media sosial. Temuan ini cukup mengejutkan karena usia siswa SMA yang berkisar 16-18 tahun biasanya memiliki sikap narsisme yang cukup tinggi dengan cara menyebarkan foto diri di media sosial, namun ini justru tidak ditemukan pada responden di kalangan siswa SMA Negeri 17 Makassar.

Secara garis besar hasil temuan data ini menunjukkan kemampuan literasi media siswa SMA Negeri 17 cukup tinggi baik pada aspek technical skill, critical understanding maupun communicative abilities.

\section{E. KESIMPULAN}

Berdasarkan hasil penelitian dan pembahasan dapat ditarik kesimpulan mengenai tingkat literasi media berbasis kompetensi individu di kalangan siswa SMA Negeri 17 Makassar sebagai berikut :

1. Tingkat kemampuan technical skill atau kemampuan mengoperasionalkan media massa khususnya media komputer serta jaringan internetnya secara akumulatif berada pada nilai $99,5 \%$

2. Tingkat kemampuan critical understanding atau kemampuan dalam menganalisis atau mengevaluasi konten media secara akumulatif berada pada nilai 74,7\% .

3. Tingkat kemampuan communicative abilities atau kemampuan dalam memproduksi konten media dan berpartisipasi aktif secara sosial melalui media secara akumulatif berada pada nilai $110,3 \%$.

4. Tingkat literasi media siswa SMA Negeri 17 Makassar adalah 94,83\% atau berada pada level Medium atau secara tersurat tingkat literasi media siwa memiliki kemampuan mengoperasikan media cukup tinggi, kemampuan dalam menganalisis dan mengevaluasi konten media cukup bagus, serta aktif dalam memproduksi konten media dan berpartisipasi secara sosial. 


\section{DAFTAR PUSTAKA}

Bungin, Burhan. (2005). Metode Penelitian Kuantitatif: Komunikasi, Ekonomi, dan Kebijakan Publik Serta Ilmu-Ilmu Sosial Lainnya. Jakarta: Kencana.

Darmastuti, $\quad$ R.,Rahardjo, $\quad$ T.,Birowo, $\quad$ M.A.,Sari, $\quad$ D.K.,Husain, M.N.,Sunarto.,Hastjarjo,S.,Febriyanto, Tomi.,Herfiady,Junaedi.F., \& Budi, S. (2012). Literasi media \& kearifan lokal, konsep dan aplikasi. Salatiga : UKSW kerjasama UBCHEA, ASPIKOM \& BUKU.

Hobbs, R. (1997). Expanding the concept of literacy. In R. Kubey (Ed.), Media literacy in the information age (pp. 163-183), New Brunswick, NJ: Transaction.

Hobbs, R. (1999). "The acquisition of media literacy skills among Australian adolescent". Journal of Broadcasting and Media. http://www.interact.uoregon.edu/MediLit/mls/readingarticles/hobbs/australia.html.

Iriantara, Y. (2009). Literasi Media, apa, mengapa dan bagaimana. Bandung: Simbiosa Rekatama Media.

Kriyantono, Rachmat. (2006). Teknik Praktis Riset Komunikasi: Disertai Contoh Praktis Riset Media, Public Relations, Advertising, Komunikasi Organisasi, Komunikasi Pemasaran. Jakarta: Kencana.

Nisfiannoor, Muhammad. (2009). Pendekatan Statistika Modern untuk Ilmu Sosial. Jakarta: Salemba Humanika.

Pratama, Aditya Hadi. (2017) "Perkembangan Pengguna Internet di Indonesia Tahun 2016 Terbesar di Dunia", https://id.techinasia.com/pertumbuhan-pengguna-internet-diindonesia-tahun-2016 (diakses pada 22 Oktober 2017)

Potter,W. J. (2004). Theory of media literacy, a cognitive approach. California: Sage Publications, Inc

Potter, W.J.(2005). Media literacy, third edition. California: Sage Publications, Inc.

Silverblatt, A., \& Eliceiri, E.M.E. (1997) Dictionary of media literacy. Westport, CT: Greenwood Press.

Winarno, Sugeng. (2014). Pemahaman Media Literacy Televisi Berbasis Personal Competences Framework (Studi Pemahaman Media Literacy Melalui Program Infotainment Pada Ibu-Ibu Perumahan Tegalgondo Asri Malang). Jurnal Humanity, 9 (2), 65-71. 